\title{
Evaluation of the Serotonergic Genes htr1A, htr1B, htr2A, and slc6A4 in Aggressive Behavior of Golden Retriever Dogs
}

\author{
L. van den Berg $\cdot$ M. Vos-Loohuis • M. B. H. Schilder • B. A. van Oost • \\ H. A. W. Hazewinkel - C. M. Wade - E. K. Karlsson - K. Lindblad-Toh • \\ A. E. Liinamo $\cdot$ P. A. J. Leegwater
}

Received: 5 April 2007/Accepted: 18 October 2007/Published online: 7 December 2007

(C) The Author(s) 2007

\begin{abstract}
Aggressive behavior displays a high heritability in our study group of Golden Retriever dogs. Alterations in brain serotonin metabolism have been described in aggressive dogs before. Here, we evaluate whether four genes of the canine
\end{abstract}

Edited by Marty Hahn.

Electronic supplementary material The online version of this article (doi:10.1007/s10519-007-9179-7) contains supplementary material, which is available to authorized users.

L. van den Berg · M. Vos-Loohuis · H. A. W. Hazewinkel · P. A. J. Leegwater

Department of Clinical Sciences of Companion Animals, Faculty of Veterinary Medicine, Utrecht University, Utrecht, The Netherlands

\section{L. van den Berg $(\square)$}

Department of Clinical Genetics, Section Medical Genomics, VU University Medical Center, van der Boechorststraat 7, 1081 BT Amsterdam, The Netherlands

e-mail: L.vandenBerg@vumc.nl

\section{B. H. Schilder}

Department of Animals, Science and Society, Faculty of Veterinary Medicine, Utrecht University, Utrecht,

The Netherlands

B. A. van Oost

American University of the Caribbean, \#1University Drive

at Jordan Road, Cupecoy, St. Maarten, NA, The Netherlands

C. M. Wade - E. K. Karlsson - K. Lindblad-Toh

The Broad Institute of Harvard and MIT, Cambridge, USA

C. M. Wade

Center for Human Genetic Research, Massachusetts General Hospital, Boston, USA

A. E. Liinamo

Department of Animal Science, Helsinki University, Helsinki, Finland serotonergic system, coding for the serotonin receptors $1 \mathrm{~A}$, $1 \mathrm{~B}$, and $2 \mathrm{~A}$, and the serotonin transporter, could play a major role in aggression in Golden Retrievers. We performed mutation screens, linkage analysis, an association study, and a quantitative genetic analysis. There was no systematic difference between the coding DNA sequence of the candidate genes in aggressive and non-aggressive Golden Retrievers. An affecteds-only parametric linkage analysis revealed no strong major locus effect on human-directed aggression related to the candidate genes. An analysis of 41 single nucleotide polymorphisms (SNPs) in the $1 \mathrm{Mb}$ regions flanking the genes in 49 unrelated human-directed aggressive and 49 unrelated nonaggressive dogs did not show association of SNP alleles, genotypes, or haplotypes with aggression at the candidate loci. We completed our analyses with a study of the effect of variation in the candidate genes on a collection of aggressionrelated phenotypic measures. The effects of the candidate gene haplotypes were estimated using the Restricted Maximum Likelihood method, with the haplotypes included as fixed effects in a linear animal model. We observed no effect of the candidate gene haplotypes on a range of aggression-related phenotypes, thus extending our conclusions to several types of aggressive behavior. We conclude that it is unlikely that these genes play a major role in the variation in aggression in the Golden Retrievers that we studied. Smaller phenotypic effects of these loci could not be ruled out with our sample size.

Keywords Dog - Aggression - Serotonin . Candidate gene $\cdot$ Linkage $\cdot$ Association

\section{Introduction}

Dogs have been living in close proximity to humans for at least 15,000 years (Clutton-Brock 1995). Behavior has 
been a strong selective factor in the domestication and breeding of dogs. According to the breed standard, Golden Retriever dogs should have a friendly character (http://www.goldenretrieverclub.nl; link accessed March 2007). However, there are reports of very aggressive Golden Retrievers (Galac and Knol 1997; Heath 1991). We recently described the behavioral phenotype of 110 Golden Retrievers referred to our clinic for aggression problems and 118 Golden Retrievers that were recruited because they were related to one or more of the aggressive dogs (van den Berg et al. 2006). The phenotypes were based on mail questionnaires and on personal interviews with dog owners. In a quantitative genetic study including 325 Golden Retrievers, we found a heritability of 0.8 for the traits of human-directed aggression and dog-directed aggression (Liinamo et al. 2007).

The influence of serotonin (5-hydroxytryptamine, 5-HT) on aggressive behavior has been studied extensively (reviewed by Berman and Coccaro 1998; Gingrich and Hen 2001; Lesch and Merschdorf 2000). There is evidence for a role of the 5-HT system in canine aggression as well. For instance, Reisner and colleagues (1996) reported decreased levels of 5-hydroxyindoleacetic acid (the major metabolite of 5-HT) in cerebrospinal fluid of dominant aggressive dogs. Badino et al. (2004) found modifications of 5-HT receptor concentrations in brains of aggressive dogs. Domestication of silver foxes, which are taxonomically close relatives of dogs, seems to cause modifications in the 5-HT system (see Trut 2001 for a review). The role of 5-HT in canine aggression is further supported by two small clinical studies, where pharmacological or dietary intervention in the 5-HT system was shown to modulate aggressive behavior (DeNapoli et al. 2000; Dodman et al. 1996).

Four genes that code for factors involved in serotonergic neurotransmission are particularly good candidates for the regulation of aggressive behavior: the serotonin receptor genes 1A (htrlA), 1B (htrlB), and 2A (htr2A), and the serotonin transporter gene (slc6A4). Serotonin receptor 1A plays a role in anxiety, stress response, and aggression (Olivier et al. 1995). HtrlA knockout mice show increased anxiety and stress response and an antidepressant-like phenotype (Heisler et al. 1998; Ramboz et al. 1998). In the above-mentioned studies of silver foxes, the researchers observed a lower density of $5-\mathrm{HT}_{1 \mathrm{~A}}$ receptors in the hypothalamus of tame foxes compared to their wild counterparts (Popova et al. 1991). Many studies have suggested involvement of $h t r l B$ in the etiology of mental disorders. For instance, Huang et al. (2003) and Sanders et al. (2002) reported an association between one of the polymorphisms in the human HTRIB gene and alcoholism, suicidality, and obsessive-compulsive disorder. Knockout mice lacking $h \operatorname{trl} B$ display increased aggression (Saudou et al. 1994). A mutation in the human HTR2A gene is associated with altered 5-HT binding, which has been implicated in schizophrenia, suicidal behavior, impaired impulse control, and aggression history (Abdolmaleky et al. 2004; Bjork et al. 2002; Khait et al. 2005). Peremans and colleagues (2003) found an increased binding index of serotonin $2 \mathrm{~A}$ receptors in cortical brain regions of impulsive aggressive dogs. A polymorphism in the promoter region of SLC6A4 influences serotonin transporter density in the brain and is associated with mental disorders in humans (Anguelova et al. 2003; Hariri et al. 2002; Lesch et al. 1996). Slc6A4 knockout mice show reduced aggression (Holmes et al. 2003).

In this paper, we test the hypothesis that there is a strong effect of variation in these genes on the variation in aggression in Golden Retrievers. We performed mutation screens of the coding DNA sequence in unrelated aggressive Golden Retrievers. In addition, we used linkage analysis to determine the likelihood of the presence of a strong aggression locus in or close to the genes in several dog families. Third, we used 50 unrelated aggressive Golden Retrievers and 50 unrelated non-aggressive Golden Retrievers to search for association of alleles of 41 SNPs flanking the candidate genes with the trait of humandirected aggression. To complete our analyses, we evaluated the effects of variation in the genes on a range of aggression-related phenotypes using the same models as in Liinamo et al. (2007), extended to include the effects of the most common candidate gene haplotypes.

\section{Materials and methods}

Animals, DNA isolation, and phenotyping

We have collected behavioral information of 328 privately owned Golden Retrievers. This group includes 162 dogs that were referred to our clinic because of their aggressive behavior ("probands") and 166 relatives of 36 probands. DNA samples were available for 281 of these dogs. In addition, we collected DNA of a cohort of random privately owned Goldens that were born between July 2002 and February 2003. No phenotypes were available for these random dogs. Genomic DNA was isolated from whole blood leucocytes using a standard protocol (Miller et al.1988). For each type of analysis (mutation analysis, linkage analysis, association analysis, and quantitative genetic analysis) we selected a study group that was suited for the study design. The study groups are described in the Supplementary Information I.

We have collected various quantitative measures of aggressiveness for the dogs (van den Berg et al. 2003a, 2006). In the linkage and association analysis we focused 
on one of these measures: the dog owners impression on human-directed aggression. Owner impressions were collected in a personal interview. We asked the owners if their dog was aggressive towards humans and the status of the dog was coded in three classes: non-aggressive (score 1), threatens (score 2), or bites (score 3). We focused on human-directed aggression because the majority of the probands were referred to our clinic for human-directed aggressive behavior. Owner impressions were available for all dogs and the quantitative genetic analyses showed that the heritability of this trait was high in our population of dogs (Liinamo et al. 2007).

\section{Mutation screening}

We analyzed the coding DNA sequence (CDS) of the four candidate genes in seven (htrlA and htrlB) or eight (htr2A and slc6A4) probands. The CDS were amplified and sequenced using overlapping primer pairs as described previously (van den Berg et al. 2004, 2005). Possible functional effects of polymorphisms were predicted with POLYPHEN (http://www.genetics.bwh.harvard.edu/cgibin/pph/polyphen.cgi). Effects of polymorphisms close to splice sites were predicted with three splice prediction programs: NetGene2 (Brunak et al. 1991), Splice Prediction by Neural Network (Reese et al. 1997), and SpliceSiteFinder (Shapiro and Senapathy 1987).

\section{Linkage analysis}

We used nine families for linkage analysis (Figs. S1-S9 of Supplementary Information I). DNA samples were available for 31 affected and 65 unaffected dogs from these families. We converted the owner impression about human-directed aggression into a dichotomous variable for the linkage analysis (see Supplementary Information I). We have described polymorphic markers for the candidate genes before (van den Berg et al. 2003b, 2004, 2005). We selected three microsatellite markers and seven single nucleotide polymorphisms for linkage analysis (see Table 1). Microsatellite markers were genotyped after PCR on an ABI 3100 Genetic Analyzer (Applied Biosystems, Foster City, CA). PCR conditions were described by van den Berg et al. (2004, 2005). GENESCAN 3.7 software was used for genotype assessment. Single nucleotide polymorphism genotyping was performed by DNA sequencing of PCR products on the ABI 3100 Genetic Analyzer (van den Berg et al. 2004, 2005). The DNA sequence chromatograms were inspected using LASERGENE software (DNASTAR, Inc., Madison, WI USA). We combined several markers into haplotypes for the genes $h t r 1 B, h t r 2 A$, and slc6A4. For dogs that were heterozygous for multiple markers, we deduced the haplotypes from the data of relatives. If this was not possible, we assigned the most frequently observed possible haplotypes to these dogs.

We performed a parametric affecteds-only linkage analysis to determine whether the candidate gene haplotypes were linked to aggressive behavior in the Golden Retriever families. Marker haplotype frequencies were determined in a group of 27 (htrlA and $h t r 2 A), 31$ (htr1B), or 26 (slc6A4) parent dogs (see Supplementary Information I). The mode of inheritance of the aggressive phenotype in our families is unclear. We therefore analyzed the data under both autosomal dominant and autosomal recessive models. The penetrance of the genotype at risk was set at 0.01 . In this way, affected dogs are assumed to have the risk allele and the software calculated likelihood that aggressive dogs share alleles by descent from a common ancestor. Unaffected dogs with the genotype at risk have no effect on the outcome of the calculation. We assumed that there were no phenocopies in the families and we assumed genetic homogeneity because all probands were related to each other within a limited number of generations (not shown). The frequency of the aggression allele was set at 0.1 to allow for multiple transmitting ancestors in the pedigrees. SUPERLINK software was used to calculate two-point logarithm of the odds (LOD) scores (Fishelson and Geiger 2002, 2004).

In order to estimate the power of the pedigrees, we calculated the maximum obtainable LOD scores. Affected individuals were assigned haplotypes $2 / 2$ in these calculations; unaffected parents were assigned haplotypes $1 / 2$; and other unaffected individuals were assigned haplotypes $1 / 1$. We assigned haplotypes 0/0 (unknown) to dogs from which we did not have a DNA sample. We assumed that there were four alleles of the hypothetical marker with equal allele frequencies.

\section{Association study}

To test for a more complex genetic effect of variants of the candidate genes, we performed an association study. Fifty aggressive Golden Retrievers were selected from our database. The main selection criteria were high estimated breeding values for human-directed aggression and as little interrelationship among the cases as possible. Nonaggressive dogs were selected for low estimated breeding values for both human- and dog-directed aggression. We avoided an excess of relationship within either the case or the control group. The non-aggressive group was completed with 25 dogs from the random group. A more 
Table 1 Markers used for linkage analysis

\begin{tabular}{|c|c|c|c|c|}
\hline$\overline{\text { Gene }^{a}}$ & Type of marker ${ }^{b}$ & $\begin{array}{l}\text { Position } \\
\text { of marker }^{c}\end{array}$ & $\begin{array}{l}\text { Alleles observed } \\
\text { (allele frequency) }^{\mathrm{d}}\end{array}$ & $\begin{array}{l}\text { Haplotypes observed } \\
\text { (haplotype frequency) }^{\mathrm{d}}\end{array}$ \\
\hline \multirow[t]{2}{*}{ htrlA } & $(\mathrm{CA})_{\mathrm{n}}$ & $* 7370$ & $297(0.5)$ & - \\
\hline & (UU160O12) & & $303(0.5)$ & \\
\hline \multirow[t]{11}{*}{$h \operatorname{trl} B$} & $\mathrm{~A} / \mathrm{C} \mathrm{SNP}$ & 157 & $\mathrm{~A}(0.58)$ & 143-A-G-T-G (0.20) \\
\hline & & & $\mathrm{C}(0.42)$ & 143-C-A-T-G (0.42) \\
\hline & G/A SNP & 246 & $\mathrm{G}(0.58)$ & 143-A-G-C-C (0.06) \\
\hline & & & A $(0.42)$ & 139-A-G-C-C (0.24) \\
\hline & T/C SNP & 955 & $\mathrm{~T}(0.69)$ & 139-A-G-T-G (0.05) \\
\hline & & & $\mathrm{C}(0.31)$ & 147-A-G-T-G (0.03) \\
\hline & G/C SNP & 1146 & $\mathrm{G}(0.69)$ & \\
\hline & & & $\mathrm{C}(0.31)$ & \\
\hline & $(\mathrm{GA})_{\mathrm{n}}$ & -68395 & $139(0.29)$ & \\
\hline & (UU18L8) & & $143(0.68)$ & \\
\hline & & & $147(0.03)$ & \\
\hline \multirow[t]{5}{*}{$h \operatorname{tr} 2 A$} & C/T SNP & IVS $2-10$ & $\mathrm{C}(0.85)$ & $128-\mathrm{C}(0.07)$ \\
\hline & & & $\mathrm{T}(0.15)$ & $130-\mathrm{C}(0.41)$ \\
\hline & $(\mathrm{CA})_{\mathrm{n}}$ & IVS2 + 1439 & $128(0.07)$ & $132-\mathrm{C}(0.37)$ \\
\hline & (UUHTR2AEX2) & & $130(0.41)$ & $132-\mathrm{T}(0.15)$ \\
\hline & & & $132(0.52)$ & \\
\hline \multirow[t]{4}{*}{ slc6A4 } & C/T SNP & 411 & $\mathrm{C}(0.75)$ & C-G (0.75) \\
\hline & & & $\mathrm{T}(0.25)$ & T-A (0.25) \\
\hline & G/A SNP & IVS9-12 & $\mathrm{G}(0.75)$ & \\
\hline & & & $\mathrm{A}(0.25)$ & \\
\hline
\end{tabular}

${ }^{a}$ htr $1 A, h \operatorname{tr} 1 \mathrm{~B}, h \operatorname{tr} 2 \mathrm{~A}=$ respectively serotonin receptor $1 \mathrm{~A}, 1 \mathrm{~B}$, and $2 \mathrm{~A}$ gene; slc $6 \mathrm{~A} 4=$ serotonin transporter gene

b SNP $=$ single nucleotide polymorphism. Names of microsatellite markers have been included in brackets

${ }^{c}$ Position refers to the coding sequence of the canine gene. We used the nomenclature recommended by den Dunnen and Antonarakis (2001): the A of the ATG start codon is designated number 1 , the nucleotide $5^{\prime}$ to this A is numbered -1 , and the nucleotide $3^{\prime}$ of the translation termination codon is $* 1$. Positions in introns refer to the nearest exon. The nomenclature of the introns is based on the human gene structure. IVS $=$ intervening sequence

d Allele and haplotype frequencies were determined in a group of 27 (htrlA and htr2A), 31 (htrlB), or 26 (slc6A4) parents

e This polymorphism is nonsynonymous

detailed description of cases and controls is provided in Supplementary Information I.

We genotyped a total number of 60,073 SNPs in these 100 Golden Retrievers using customized Affymetrix Genotyping Arrays. The SNPs were selected for the chip using a scoring system that optimized the SNPs accounting for low repeat content, low likelihood of SNPs in the assay probe sequences and their distribution over the genome as a whole (Lindblad-Toh 2007; personal communication). Twenty 32-mer probes interrogated each locus with genotyping calls made using the algorithm BRLMM (http://www.affymetrix.com) which analyses intensities for sets of probes that interrogate both forward and reverse sequences with perfect match and mismatched probes. Dogs with call rates of lower than 50\% were discarded from the analysis. The total set of SNPs was filtered for genotype call probability, heterozygosity rate, and call rate across a large set of dogs, reducing the dataset to 26,625 SNPs. From this set, only SNPs within $1 \mathrm{Mb}$ of the four candidate genes were used for the analysis described in this paper. There were 29 SNPs within $1 \mathrm{Mb}$ of htrlA, 20 within $1 \mathrm{Mb}$ of htrlB, 25 within $1 \mathrm{Mb}$ of htr $2 A$, and 20 within $1 \mathrm{Mb}$ of slc6A4. From these SNPs, we selected 43 SNPs with a minor allele frequency $>0.05$ and call rates of $>0.75$.

We used Haploview software version 4.0 (Barrett et al. 2005) for the analysis of the presence of HardyWeinberg equilibrium (HWE), the local association analysis, and the calculation of pairwise linkage disequilibrium (LD) between the SNPs. A HWE $P$-value cutoff of 0.001 was used. We used Bonferonni correction to account for multiple testing in the association analysis. Genotype frequencies in cases and controls were compared with Chi square tests using SPSS software. Two 
tailed Fisher's exact tests were used when the number of expected cases was less than 5 in more than $20 \%$ of the categories. Haplotype blocks were formed using three methods in Haploview (confidence intervals, four gamete rule, and solid spine of LD). For all possible combinations we performed 10,000 permutations to obtain empirical $P$ values for haplotype association tests. We used the genetic power calculator prepared by Purcell to estimate the power of the association analysis (http://www.pngu.mgh.harvard.edu/ purcell/gpc/). The following assumptions were made: high-risk allele frequency $=0.1$; prevalence $=0.01$. The mean pairwise $\mathrm{D}^{\prime}$ between the SNPs flanking a candidate gene was used as an estimate of the local $\mathrm{D}^{\prime}$ in these estimations. Calculations were performed for two different genotype relative risks: 2 (genotype relative risk $\mathrm{Aa}=2$; genotype relative risk $\mathrm{AA}=4$ ) and 5 (genotype relative risk $\mathrm{Aa}=5$; genotype relative risk $\mathrm{AA}=10)$.

\section{Quantitative genetic analysis}

In addition to the owner impression on human-directed aggression and dog-directed aggression, we collected a variety of other aggression-related behavioral measures using the canine behavioral assessment and research questionnaire (CBARQ; Hsu and Serpell 2003). As described in Liinamo et al. (2007), these measures were of three types: original CBARQ items (27 items on the aggressiveness of the dog in various everyday situations), shortened CBARQ scores (scores based on questions that addressed stranger-directed, owner-directed, and strange dog-directed aggression), and CBARQ factors (scores based on questions about stranger-directed, owner-directed, and strange dog-directed, and familiar dog-directed aggression). For further explanation of the measures and the difference between shortened CBARQ scores and CBARQ factors, see Liinamo et al. (2007).

The effects of the haplotypes of the serotonergic genes on the different aggression measures were estimated with Restricted Maximum Likelihood (REML) method (Patterson and Thompson 1971), using univariate analyses and an animal model with the VCE4.2.4 software (Groeneveld 1997). The analyses were an extension of the analyses outlined in Liinamo et al. (2007), using similar linear animal model methodology, but this time also including the haplotype classes of the dogs for the four studied loci as additional fixed effects in the model. For instance, the linear animal model that was assumed in the analyses for owner impression traits was:

$$
\begin{aligned}
y_{i j k l m n o}= & \mu+\operatorname{sex}_{i}+a g e_{j}+h \operatorname{tr} 1 a_{k}+h \operatorname{tr} 1 b_{l}+h t r 2 a_{m} \\
& +\operatorname{slc} 64_{n}+a_{o}+e_{o}
\end{aligned}
$$

where $y_{\text {iiklmno }}$ is the observed value for the owner impression score for animal $o ; \mu$ the general mean in the population; sex the fixed effect of the reproductive status ( $i=1-4$, with ${ }^{i} 1=$ intact male, $2=$ castrated male, $3=$ intact female, and $4=$ castrated female); age the fixed effect of the age $j\left(j=1-11\right.$, with $1=0.5-1^{j}$ year old, $2=1-2$ years old, ..,10 =9-10 years old, and $11=$ over 10 years old); htrla, htrlb, htr $2 a$, and slc6a4 the fixed effects of the respective haplotype classes, $a^{n}$ the random additive genetic effect (i.e., polygenic breeding value) of the animal $o$, and $e$ the random residual effect related to the animal $o$. The age and reproductive status of the dogs had been recorded at the same time as the owner impressions. The haplotype classes were formed so that the most common haplotypes formed separate classes, the very rare haplotypes were all combined in one class, and the unknown haplotypes were classified as a separate class (see Table 4).

\section{Results}

Mutation screening of the coding DNA sequence

The coding DNA sequence of each candidate gene was scanned for mutations in seven ( $h$ trlA and $h t r l B)$ or eight (htr2A and slc6A4) aggressive Golden Retrievers. Analysis of the CDS in non-aggressive Golden Retrievers has been described by van den Berg et al. (2004; 2005). There was no variation in the CDS of $h t r l A$ and $h t r 2 A$ in the Golden Retrievers. We observed five SNPs in the CDS of htrlB and one SNP in the CDS of slc6A4. The allele distribution of these SNPs in the two groups of Golden Retrievers did not indicate a role in aggressive behavior. In conclusion, there seems to be no systematic difference between the CDS of the candidate genes in aggressive and nonaggressive Golden Retrievers.

\section{Linkage analysis}

We observed two alleles for htrlA marker UU160012 (Table 1). The four SNPs in $h t r l B$ were fully in LD $\left(\mathrm{D}^{\prime}=1\right)$. The SNPs displayed six haplotypes in the Goldens, three of which were rare (frequency $<0.1$ ). We detected four haplotypes of $h t r 2 A$ in the Golden Retrievers. The two SNPs in slc6A4 were fully in LD and formed two haplotypes in the dogs. In the nine families that we used for linkage analysis, haplotypes were deduced with certainty in $86 \%$ of the dogs for $h t r 1 B, 100 \%$ for $h t r 2 A$, and $87 \%$ for slc6A4. We calculated the maximum achievable LOD score using hypothetical genotypes. The maximum LOD 
Table 2 Results from the ODDS (LOD) scores ${ }^{\mathrm{a}}$

\begin{tabular}{lcl}
\hline Gene & Autosomal dominant & Autosomal recessive \\
\hline htrlA & 0.26 & -0.30 \\
htr $1 B$ & -0.72 & -2.3 \\
htr $2 A$ & -1.0 & -2.1 \\
slc6A4 & 0.030 & -1.2 \\
Maximum & 2.8 & 5.3
\end{tabular}

${ }^{a}$ LOD scores were calculated with the following assumptions: frequency of the "aggression allele" $=0.1$; penetrance of the "aggression allele" $=0.01 ; \theta=0$. Marker haplotype frequencies were deduced from a group of parents

score generated by our pedigrees was 2.8 at recombination fraction $\theta=0$ assuming a dominant mode of inheritance (Table 2). Under a recessive model, the maximum LOD score was 5.3 at $\theta=0$. The families are therefore theoretically powerful enough to prove linkage under a recessive model and powerful enough to provide a good indication of the presence of linkage under a dominant model. There was no significant linkage of any of the candidate genes with the aggressive phenotype (Table 2). LOD scores varied from -1.0 to +0.26 assuming dominant inheritance and from -2.3 to -0.30 assuming recessive inheritance. The highest LOD scores were obtained for htrlA (+0.26 under a dominant model and -0.30 under a recessive model).

\section{Association study}

Two dogs (one case and one control) were discarded from the association analysis because they had call rates lower than 50\%. Mean call rates in the other 98 dogs were $92 \%$ for SNPs flanking htrlA, 94\% for htrlB, 93\% for htr2A, and $93 \%$ for slc6A4. There were 43 SNPs with a minor allele frequency $>0.05$ and call rates of $>0.75$ that occurred within $1 \mathrm{Mb}$ of the candidate genes. The genotype frequencies of BICF2P1093362 for $h$ trlB and BICF2P969902 for slc6A4 deviated from $\mathrm{HWE}$ in control dogs ( $P=4.42 \mathrm{E}-14$ and $P=5.242 \mathrm{E}-12$, respectively). All but one dog in both case and control group had heterozygous genotypes for these SNPs. We concluded that the data for these two SNPs was artefactual and they were excluded from further analyses. The observed genotype frequencies of the other 41 SNPs were in HWE in controls ( $P$ values are listed in Table S2 in Supplementary Information II). The final SNP set used for the association analysis consisted of 12 SNPs flanking htrlA, 11 flanking htrlB, 8 flanking $h t r 2 A$, and 10 flanking slc6A4 (Table 3).

The power of our association analysis depends on the local extent of LD. The mean $r^{2}$ between the SNPs flanking htrlA was 0.36 and the mean $\mathrm{D}^{\prime}$ between these SNPs was
0.89. Mean $r^{2}$ values were $0.23,0.25$, and 0.21 for $h \operatorname{tr} 1 B$, $h t r 2 A$, and slc6A4, respectively. Mean $\mathrm{D}^{\prime}$ values were 0.80 , 0.72 , and 0.88 for $h t r l B$, htr $2 A$, and slc $6 A 4$, respectively. When the marker allele frequency is 0.1 , the power to detect a variant with a relative risk of 5 with 49 cases and 49 controls would be 0.91 for htrlA, 0.85 for htrlB, 0.78 for $h t r 2 A$, and 0.90 for slc6A4. Additional power estimations are provided in Fig. S10 in Supplementary Information II.

The allele frequencies of the SNPs did not differ significantly between cases and controls after correction for multiple testing (Table 3). Genotype frequencies also did not display significant differences between cases and controls (see Table S2 in Supplementary Information II). We also analyzed the association of haplotypes with the phenotype. No significant associations were found (data not shown). In conclusion, there seemed to be no association between alleles, genotypes or haplotypes of SNPs that flank the candidate genes and human-directed aggression in the Golden Retrievers.

\section{Quantitative genetic analysis}

We completed our analyses with a study of the effect of variation in the candidate genes on a collection of aggression-related phenotypic measures. The haplotype effects were studied on owner impressions on human- and dog-directed aggression, the original CBARQ items related to stranger- and owner-directed aggression, the shortened CBARQ scores and the CBARQ factors. The haplotypes did not have a significant effect on any of the studied measures, i.e. the heritability estimates of the measures remained similar to the results presented in Liinamo et al. (2007) in spite of incorporation of the haplotypes in the mixed model. The results for owner impressions on humanand dog-directed aggression, which are the most reliable estimates due to the largest number of observations, are presented in Table 4. In conclusion, the large genetic variability between the dogs could not be explained by the serotonergic genes studied in this paper.

\section{Discussion}

We collected behavioral information and DNA samples of $281 \mathrm{dogs}$ over a period of 10 years. Dogs were selected from this collection to evaluate four genes involved in serotonin metabolism by four methods: DNA sequence analysis of the coding region of the genes, genetic linkage analysis, genetic association analysis, and quantitative genetic analysis. The results indicate that it is unlikely that there is a major locus effect of one of the genes on aggression in the Golden Retrievers that we studied. 


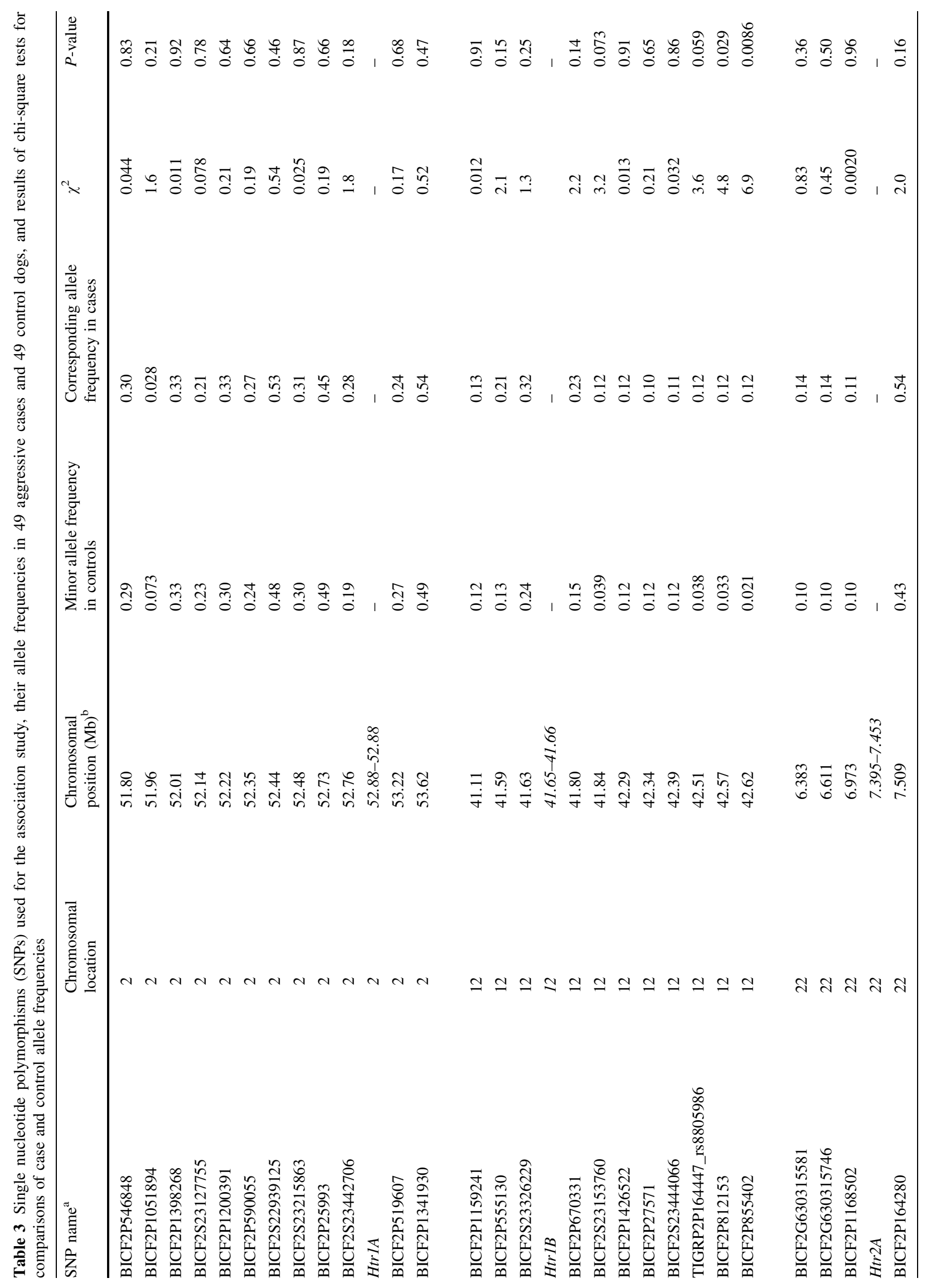


62

Behav Genet (2008) 38:55-66

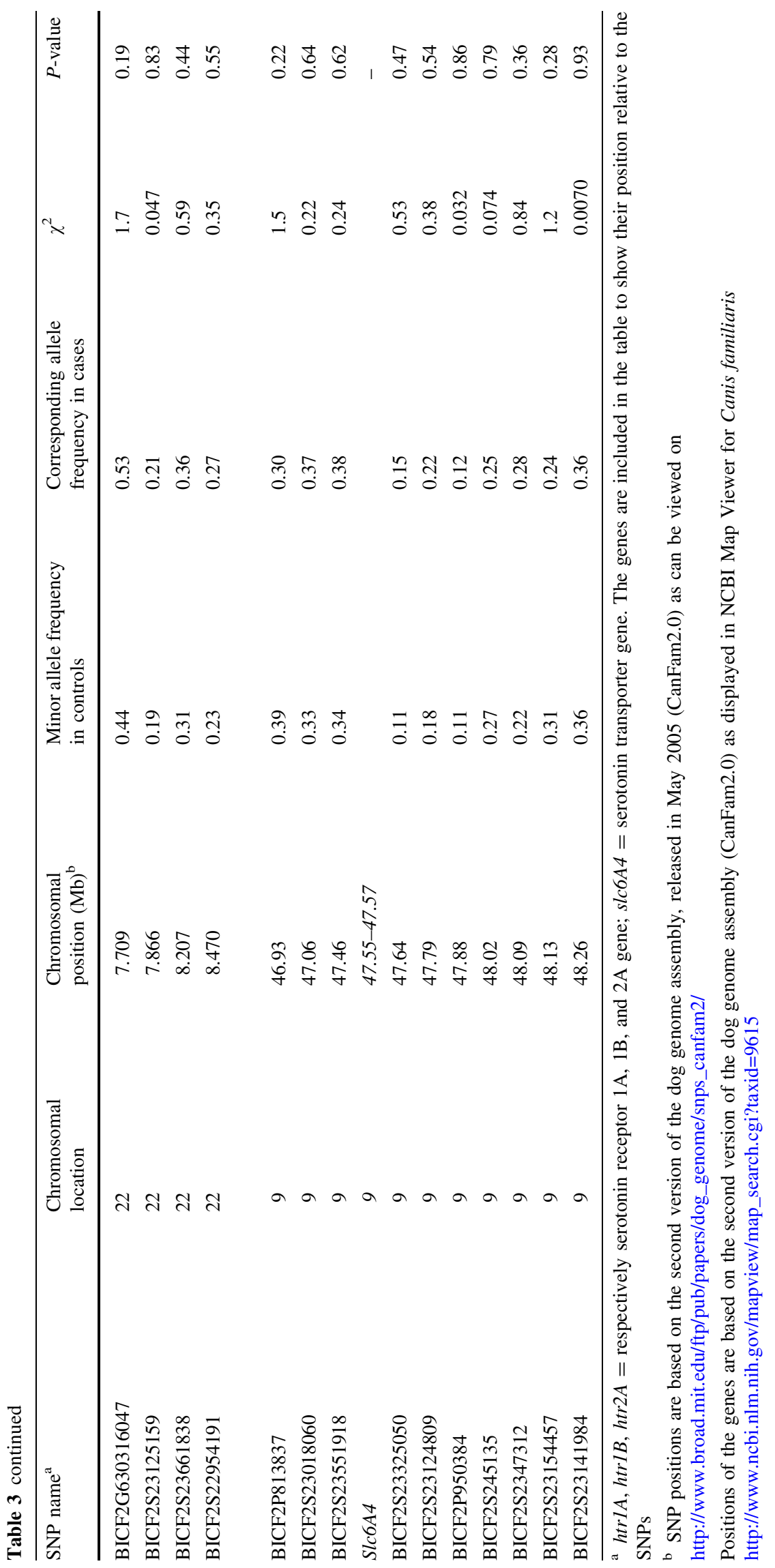

型 Springer 
Table 4 The effects of the studied genotypes (htrlA) or haplotypes (htrlB, htr2A, and slc6A4) on owner impressions of human-directed aggression and dog-directed aggression in 320 dogs

\begin{tabular}{|c|c|c|c|}
\hline \multirow[t]{2}{*}{ Genotype or haplotype class ${ }^{\mathrm{a}}$} & \multirow[t]{2}{*}{ Number of animals } & \multicolumn{2}{|c|}{ Effect relative to class 'unknown' } \\
\hline & & $\begin{array}{l}\text { Human-directed } \\
\text { aggression }\end{array}$ & $\begin{array}{l}\text { Dog-directed } \\
\text { aggression }\end{array}$ \\
\hline \multicolumn{4}{|l|}{ htrlA } \\
\hline Unknown & 44 & 0.00 & 0.00 \\
\hline $297 / 297$ & 74 & 0.028 & 0.11 \\
\hline $297 / 303$ & 111 & 0.24 & 0.054 \\
\hline $297 / 305$ & 15 & 0.012 & 0.089 \\
\hline $303 / 303$ & 62 & 0.18 & 0.085 \\
\hline $303 / 305$ & 10 & -0.11 & -0.067 \\
\hline Other & 4 & -0.046 & -0.17 \\
\hline \multicolumn{4}{|l|}{$h \operatorname{tr} 1 B$} \\
\hline Unknown & 166 & 0.00 & 0.00 \\
\hline 143-A-G-T-G/143-A-G-T-G & 20 & -0.73 & 0.28 \\
\hline 143-A-G-T-G /143-C-A-T-G & 8 & -0.63 & -0.19 \\
\hline 143-A-G-T-G /139-A-G-C-C & 19 & 0.11 & 0.19 \\
\hline 143-C-A-T-G/143-C-A-T-G & 41 & -0.17 & 0.13 \\
\hline 143-C-A-T-G /143-A-G-C-C & 10 & -0.021 & 0.059 \\
\hline 143-C-A-T-G /139-A-G-C-C & 30 & 0.0006 & 0.32 \\
\hline 139-A-G-C-C/139-A-G-C-C & 9 & 0.24 & 0.11 \\
\hline Other & 17 & 0.15 & 0.36 \\
\hline \multicolumn{4}{|l|}{$h t r 2 A$} \\
\hline Unknown & 114 & 0.00 & 0.00 \\
\hline $132-\mathrm{C} / 132-\mathrm{C}$ & 40 & -0.15 & -0.19 \\
\hline $132-\mathrm{C} / 130-\mathrm{C}$ & 60 & -0.27 & -0.023 \\
\hline $132-\mathrm{C} / 132-\mathrm{T}$ & 28 & -0.22 & 0.073 \\
\hline $132-\mathrm{C} / 128-\mathrm{C}$ & 15 & -0.38 & -0.43 \\
\hline $130-\mathrm{C} / 130-\mathrm{C}$ & 21 & -0.33 & -0.072 \\
\hline $130-\mathrm{C} / 132-\mathrm{T}$ & 22 & 0.10 & -0.19 \\
\hline $130-\mathrm{C} / 128-\mathrm{C}$ & 9 & -0.52 & -0.29 \\
\hline Other & 11 & 0.33 & -0.036 \\
\hline \multicolumn{4}{|l|}{ slc $6 A 4$} \\
\hline Unknown & 103 & 0.00 & 0.00 \\
\hline $\mathrm{C}-\mathrm{G} / \mathrm{C}-\mathrm{G}$ & 116 & 0.025 & -0.23 \\
\hline C-G/T-A & 94 & 0.14 & -0.23 \\
\hline Other & 7 & 0.079 & -0.10 \\
\hline
\end{tabular}

The genetic study of the variation of aggression in Golden Retrievers is a promising tool to identify the molecular systems involved in aggression. The relative ease to find disease loci in the dog genome compared to the human genome is the result of the population structure of dog breeds. Within a breed, Lindblad-Toh and colleagues (2005) observed a limited number of common haplotypes per genomic region. In addition, LD in dog breeds extends over at least 50-fold greater distances than in human populations. These characteristics make the dog highly suited for molecular genetic studies of complex traits (Sutter and Ostrander 2004).
We did not detect mutations in the CDS of the genes specific for aggressive dogs. All SNPs except A157C in htrlB were synonymous. This $\mathrm{A} 157 \mathrm{C}$ variation, resulting in an isoleucine/leucine polymorphism of amino acid 53, was predicted to be functionally insignificant by POLYPHEN. The genes htr $2 A$ and slc6A4 contain SNPs close to splice sites (at position IVS2-10 and IVS9-12, respectively) that could theoretically affect splicing. However, the polymorphisms did not have a large effect on splice site prediction by three software programs. We performed mutation screening in a limited number of dogs and it is possible that we have missed rare alterations in the genes. 
Apart from this limitation, we conclude that there is no common variant acting on protein structure that contributes to the variation in aggression in our Golden Retriever sample.

We used linkage analysis to evaluate the likelihood that there is a major aggression-influencing variant in the chromosomal regions surrounding the coding exons. The affecteds only parameters that we used in the calculations are a simplification with the assumption that all affected dogs of a family have the genotype at risk but unaffected dogs can have any genotype at the aggression locus. A LOD score of 3 is usually considered as evidence for linkage, whereas LOD scores below -2 exclude the gene. A power calculation with simulated genotypes was not feasible in this study due to the complexity of some pedigrees with multiple loops. Instead, we calculated the maximum achievable LOD scores to get an impression of the power embodied in the pedigrees. We assumed full informativeness of the markers in these calculations, but in reality, we expect the markers to have limited informativeness. Realistic obtainable LOD scores would then be lower than the maximum values that we presented in Table 2. These LOD scores are too low to obtain significant results, but they provide a means to set the obtained results into perspective. The LOD scores for $h t r l B$ and $h t r 2 A$ were low compared to the maximum obtainable scores. A major role of these genes is unlikely. The results for $h t r l A$ and slc6A4 are less conclusive. This is probably the result of the poor informativeness of the markers. For both genes, we observed only two alleles or haplotypes with high frequencies. Typing of additional markers might help to definitively exclude the genes. However, in the light of the observed low level of variation it is unlikely that htrlA and slc6A4 have a strong effect on aggression in the Golden Retriever families.

Our linkage analysis does not account for genetic heterogeneity or phenocopies. We have thus only tested for a very strong major locus effect. In reality, the aggressiveness in the Golden Retrievers may be more complex. We therefore used a third study design to investigate the candidate genes: association analysis. For this analysis, we used data from a large-scale genotyping project in 100 Golden Retrievers. Our power calculations demonstrate that this sample size is expected to be sufficient to detect variants that confer a high relative risk for a range of marker allele frequencies. From the total set of 60,073 SNP genotypes, we selected 41 SNPs that flank the candidate genes. We found no association between alleles, genotypes or haplotypes of these SNPs flanking the candidate genes and human-directed aggression of the Golden Retrievers.

We focused on human-directed aggression in the affecteds-only linkage analysis and the association study. In our quantitative genetic analysis, we studied additional types of aggression. There is no consensus in the literature on how aggression should be subdivided (Houpt and Willis 2001; Jacobs et al. 2003; Serpell and Jagoe 1995). There are indications that various types of aggression have a distinct genetic basis. For instance, selection of rats and silver foxes for reduced fear-induced aggression towards humans did not change predatory or inter-male aggression (Naumenko et al. 1989; Popova et al. 1993). This suggests that molecular genetic studies of aggressive behavior should focus on specific classes of aggression. However, reduced aggressiveness towards man in the rats and foxes was accompanied by reduced fear of novelties and irritable aggression, indicating that there is overlap between classes. As long as the genetic roots of aggressive behavior are poorly understood, it will remain impossible to design a classification that reflects the genetic basis.

In conclusion, none of the four methods of analysis provided evidence for a strong effect of variants of the candidate genes on aggression in the Golden Retrievers that we studied. These results seem to contradict reports of the involvement of the candidate genes in the regulation of aggressive behavior. However, the study designs that we used are not powerful enough to detect variants of small effect. We can therefore not rule out the possibility that variation in the candidate genes has a smaller genetic effect on aggression. In addition, our results cannot be construed as evidence against a major role for these genes in aggression in other dog breeds. Possibly, other genes in the serotonin pathway play a role. With the completion of the dog genome project, genome-wide association studies have become feasible in dogs (Lindblad-Toh et al. 2005). This opens the opportunity for finding genes that have not been associated with aggression up to date. Such studies are in progress.

Acknowledgments The "Jubileumfonds Hoogleraren Diergeneeskunde" supported this work. We thank Laura Kwant, Frank van Steenbeek, and Tara Biagi for technical assistance, Harry van Engelen for collection of the blood samples, and the dog owners for their cooperation with our project.

Open Access This article is distributed under the terms of the Creative Commons Attribution Noncommercial License which permits any noncommercial use, distribution, and reproduction in any medium, provided the original author(s) and source are credited.

\section{References}

Abdolmaleky HM, Faraone SV, Glatt SJ, Tsuang MT (2004) Metaanalysis of association between the T102C polymorphism of the $5 H T 2 a$ receptor gene and schizophrenia. Schizophr Res 67: $53-62$

Anguelova M, Benkelfat C, Turecki G (2003) A systematic review of association studies investigating genes coding for serotonin 
receptors and the serotonin transporter: II. Suicidal behavior. Mol Psychiatry 8:646-653

Badino P, Odore R, Osella MC, Bergamasco L, Francone P, Girardi C, Re G (2004) Modifications of serotonergic and adrenergic receptor concentrations in the brain of aggressive Canis familiaris. Comp Biochem Physiol Mol Integr Physiol 139:343-350

Barrett JC, Fry B, Maller J, Daly MJ (2005) Haploview: analysis and visualization of LD and haplotype maps. Bioinformatics 21: 263-265

Berman ME, Coccaro EF (1998) Neurobiologic correlates of violence: relevance to criminal responsibility. Behav Sci Law 16:303-318

Bjork JM, Moeller FG, Dougherty DM, Swann AC, Machado MA, Hanis CL (2002) Serotonin 2a receptor T102C polymorphism and impaired impulse control. Am J Med Genet 114:336-339

Brunak S, Engelbrecht J, Knudsen S (1991) Prediction of human mRNA donor and acceptor sites from the DNA sequence. J Mol Biol 220:49-65

Clutton-Brock J (1995) Origins of the dog: domestication and early history. In: Serpell J (ed) The domestic dog-its evolution, behaviour and interactions with people. Cambridge University Press, Cambridge, pp 8-20

DeNapoli JS, Dodman NH, Shuster L, Rand WM, Gross KL (2000) Effect of dietary protein content and tryptophan supplementation on dominance aggression, territorial aggression, and hyperactivity in dogs. J Am Vet Med Assoc 217:504-508

den Dunnen JT, Antonarakis SE (2001) Nomenclature for the description of human sequence variations. Hum Genet 109: $121-124$

Dodman NH, Donnelly R, Shuster L, Mertens P, Rand W, Miczek K (1996) Use of fluoxetine to treat dominance aggression in dogs. J Am Vet Med Assoc 209:1585-1587

Fishelson M, Geiger D (2002) Exact genetic linkage computations for general pedigrees. Bioinformatics 18(Suppl 1):S189-S198

Fishelson M, Geiger D (2004) Optimizing exact genetic linkage computations. J Comput Biol 11:263-275

Galac S, Knol BW (1997) Fear-motivated aggression in dogs: patient characteristics, diagnosis and therapy. Animal Welfare 6:9-15

Gingrich JA, Hen R (2001) Dissecting the role of the serotonin system in neuropsychiatric disorders using knockout mice. Psychopharmacology (Berl) 155:1-10

Groeneveld E (1997) VCE4 User's Guide and Reference Manual. Version 1.0. URL: http://www.3.tzv.fal.de/ eg/vce4/manual/ manual.html link accessed 8-2007

Hariri AR, Mattay VS, Tessitore A, Kolachana B, Fera F, Goldman D, Egan MF, Weinberger DR (2002) Serotonin transporter genetic variation and the response of the human amygdala. Science 297: $400-403$

Heath S (1991) Aggression in Golden Retrievers. Vet Rec 128:459

Heisler LK, Chu HM, Brennan TJ, Danao JA, Bajwa P, Parsons LH, Tecott LH (1998) Elevated anxiety and antidepressant-like reponses in serotonin 5-HT1A receptor mutant mice. Proc Natl Acad Sci USA 95:15049-15054

Holmes A, Murphy DL, Crawley JN (2003) Abnormal behavioral phenotypes of serotonin transporter knockout mice: parallels with human anxiety and depression. Biol Psychiatry 54:953-959

Houpt KA, Willis MB (2001) Genetics of behaviour. In: Ruvinsky A, Sampson J (eds) The genetics of the dog. CABI Publishing, New York, pp 371-400

Hsu Y, Serpell JA (2003) Development and validation of a questionnaire for measuring behavior and temperament traits in pet dogs. J Am Vet Med Assoc 223:1293-1300

Huang YY, Oquendo MA, Friedman JM, Greenhill LL, Brodsky B, Malone KM, Khait V, Mann JJ (2003) Substance abuse disorder and major depression are associated with the human 5-HT1B receptor gene (HTR1B) G861C polymorphism. Neuropsychopharmacology 28:163-169

Jacobs C, de Keuster T, Simoens P (2003) Assessing the pathological extent of aggressive behaviour in dogs. A review of the literature. Vet Q 25:53-60

Khait VD, Huang YY, Zalsman G, Oquendo MA, Brent DA, Harkavy-Friedman JM, Mann JJ (2005) Association of serotonin 5-HT2A receptor binding and the T102C polymorphism in depressed and healthy Caucasian subjects. Neuropsychopharmacology 30:166-172

Lesch KP, Bengel D, Heils A, Sabol SZ, Greenberg BD, Petri S, Benjamin J, Muller CR, Hamer DH, Murphy DL (1996) Association of anxiety-related traits with a polymorphism in the serotonin transporter gene regulatory region. Science 274: $1527-1531$

Lesch KP, Merschdorf U (2000) Impulsivity, aggression \& serotonin: a molecular psychobiological perspective. Behav Sci Law 18: $581-604$

Liinamo A-E, van den Berg L, Leegwater PAJ, Schilder MBH, van Arendonk JAM, van Oost BA (2007) Genetic variation in aggression related traits in Golden Retriever dogs. Appl Anim Beh Sci 104:95-106

Lindblad-Toh K, Wade CM, Mikkelsen TS, Karlsson EK, Jaffe DB, Kamal M, Clamp M, Chang JL, Kulbokas EJ III, Zody MC et al (2005) Genome sequence, comparative analysis and haplotype structure of the domestic dog. Nature 438:803-819

Miller SA, Dykes DD, Polesky HF (1988) A simple salting out procedure for extracting DNA from human nucleated cells. Nucleic Acids Res 16:1215

Naumenko EV, Popova NK, Nikulina EM, Dygalo NN, Shishkina GT, Borodin PM, Markel AL (1989) Behavior, adrenocortical activity, and brain monoamines in Norway rats selected for reduced aggressiveness towards man. Pharmacol Biochem Behav 33:85-91

Olivier B, Mos J, van Oorschot R, Hen R (1995) Serotonin receptors and animal models of aggressive behavior. Pharmacopsychiat 28(Suppl):80-90

Patterson HD, Thompson R (1971) Recovery of interblock information when block sizes are unequal. Biometrika 58:545-554

Peremans K, Audenaert K, Coopman F, Blanckaert P, Jacobs F, Otte A, Verschooten F, van Bree $\mathrm{H}$, van Heeringen $\mathrm{K}$, Mertens $\mathrm{J}$, Slegers G, Dierckx R (2003) Estimates of regional cerebral blood flow and 5-HT2A receptor density in impulsive, aggressive dogs with 99mTc-ECD and 123I-5-I-R91150. Eur J Nucl Med Mol Imaging 30:1538-1546

Popova NK, Voitenko NN, Kulikov AV, Avgustinovich DF (1991) Evidence for the involvement of central serotonin in mechanism of domestication of silver foxes. Pharmacol Biochem Behav 40: $751-756$

Popova NK, Nikulina EM, Kulikov AV (1993). Genetic analysis of different kinds of aggressive behavior. Behav Genet 23: $491-497$

Ramboz S, Oosting R, Amara DA, Kung HF, Blier P, Mendelsohn M, Mann JJ, Brunner D, Hen R (1998) Serotonin receptor 1A knockout: an animal model of anxiety-related disorder. Proc Natl Acad Sci USA 95:14476-14481

Reese MG, Eeckman FH, Kulp D, Haussler D (1997) Improved splice site detection in Genie. J Comput Biol 4:311-323

Reisner IR, Mann JJ, Stanley M, Huang YY, Houpt KA (1996) Comparison of cerebrospinal fluid monoamine metabolite levels in dominant-aggressive and non-aggressive dogs. Brain Res 714: $57-64$

Sanders AR, Duan J, Gejman PV (2002) DNA variation and psychopharmacology of the human serotonin receptor 1B (HTR1B) gene. Pharmacogenomics 3:745-762 
Saudou F, Amara DA, Dierich A, LeMeur M, Ramboz S, Segu L, Buhot MC, Hen R (1994) Enhanced aggressive behavior in mice lacking 5-HT1B receptor. Science 265:1875-1878

Serpell JA, Jagoe JA (1995) Early experience and the development of behaviour. In: Serpell J (ed) The domestic dog: its evolution, behaviour, and interactions with people. Cambridge University Press, Cambridge, pp 79-102

Shapiro MB, Senapathy P (1987) RNA splice junctions of different classes of eukaryotes: sequence statistics and functional implications in gene expression. Nucleic Acids Res 15:7155-7174

Sutter NB, Ostrander EA (2004) Dog star rising: the canine genetic system. Nat Rev Genet 5:900-910

Trut LN (2001) Experimental studies of early canid domestication. In: Ruvinsky A, Sampson J (eds) The genetics of the dog. CABI Publishing, New York, pp 15-41

Van den Berg L, Schilder MBH, Knol BW (2003a) Behavior genetics of canine aggression: behavioral phenotyping of Golden
Retrievers by means of an aggression test. Behav Genet 33:469-483

Van den Berg L, Versteeg S, Van Oost BA (2003b) Isolation and characterization of the canine serotonin receptor $1 \mathrm{~A}$ gene (htr1A). J Heredity 94:49-56

Van den Berg L, Imholz S, Versteeg SA, Leegwater PAJ, Zijlstra C, Bosma AA, Van Oost BA (2004) Isolation and characterization of the canine serotonin receptor $1 \mathrm{~B}$ gene (htr1B). Gene 326: 131-139

Van den Berg L, Kwant L, Hestand MS, van Oost BA, Leegwater PAJ (2005) Structure and variation of three canine genes involved in serotonin binding and transport: the serotonin receptor $1 \mathrm{~A}$ gene (htr1A), serotonin receptor $2 \mathrm{~A}$ gene (htr2A), and serotonin transporter gene (slc6A4). J Heredity 96(7):786-796

Van den Berg L, Schilder M, de Vries H, Leegwater PAJ, van Oost BA (2006) Phenotyping of aggressive behaviour in Golden Retriever dogs with a questionnaire. Behav Genet 36(6):882-902 